\title{
The effectiveness of a multidisciplinary intervention strategy for the treatment of symptomatic joint hypermobility in childhood: a randomised, single Centre parallel group trial (The Bendy Study)
}

Peter Bale ${ }^{\text {* }^{*}}$, Vicky Easton ${ }^{1}$, Holly Bacon ${ }^{1}$, Emma Jerman², Laura Watts ${ }^{1,3}$, Garry Barton ${ }^{3}$, Allan Clark ${ }^{3}$, Kate Armon ${ }^{1}$ and Alex J. MacGregor ${ }^{1,3}$

\begin{abstract}
Introduction: Joint hypermobility is common in childhood and can be associated with musculoskeletal pain and dysfunction. Current management is delivered by a multidisciplinary team, but evidence of effectiveness is limited. This clinical trial aimed to determine whether a structured multidisciplinary, multisite intervention resulted in improved clinical outcomes compared with standard care.

Method: A prospective randomised, single centre parallel group trial comparing an 8-week individualised multidisciplinary intervention programme (bespoke physiotherapy and occupational therapy in the clinical, home and school environment) with current standard management (advice, information and therapy referral if deemed necessary).

The primary endpoint of the study was between group difference in child reported pain from baseline to 12 months as assessed using the Wong Baker faces pain scale. Secondary endpoints were parent reported pain (100 $\mathrm{mm}$ visual analogue scale), parent reported function (child health assessment questionnaire), child reported quality of life (child health utility 9-dimensional assessment), coordination (movement assessment battery for children version 2) and grip strength (handheld dynamometer).
\end{abstract}

Results: 119 children aged 5 to 16 years, with symptomatic hypermobility were randomised to receive an individualised multidisciplinary intervention (I) $(n=59)$ or standard management $(S)(n=60)$. Of these, 105 completed follow up at 12 months. No additional significant benefit could be shown from the intervention compared to standard management. However, there was a statistically significant improvement in child and parent reported pain, coordination and grip strength in both groups. The response was independent of the degree of hypermobility.

Conclusion: This is the first randomised controlled trial to compare a structured multidisciplinary, multisite intervention with standard care in symptomatic childhood hypermobility. For the majority, the provision of education and positive interventions aimed at promoting healthy exercise and self-management was associated with significant benefit without the need for more complex interventions.

(Continued on next page)

\footnotetext{
* Correspondence: peterbale@doctors.net.uk

${ }^{1}$ Norfolk and Norwich University Hospital NHS Trust, Colney Lane, Norwich, UK

Full list of author information is available at the end of the article
}

(c) The Author(s). 2019 Open Access This article is distributed under the terms of the Creative Commons Attribution 4.0 International License (http://creativecommons.org/licenses/by/4.0/), which permits unrestricted use, distribution, and reproduction in any medium, provided you give appropriate credit to the original author(s) and the source, provide a link to the Creative Commons license, and indicate if changes were made. The Creative Commons Public Domain Dedication waiver (http://creativecommons.org/publicdomain/zero/1.0/) applies to the data made available in this article, unless otherwise stated. 
(Continued from previous page)

Trial registration: The trial was registered prospectively with the national database at the Clinical Research

Network (UKCRN Portfolio 9366). The trial was registered retrospectively with ISRCTN (ISRCTN86573140).

Keywords: Hypermobility, Pain, Children and young people, Physiotherapy, Occupational therapy

\section{Background}

Joint hypermobility is common in childhood, with a high prevalence reported in the literature when adult criteria are applied [1-7]. Hypermobile joints are not synonymous with morbidity; for example, gymnasts, musicians and athletes can use this flexibility to their advantage $[8$, 9]. However, pain has been reported to occur in as many as $55 \%$ of all children with hypermobility [10] and children with symptomatic hypermobility account for a large proportion of referrals to tertiary paediatric rheumatology services [11]. Symptomatic hypermobility (previously referred to as joint hypermobility syndrome (JHS)) is varied in its presentation and is challenging both to diagnose and manage, reflected by a wide variation in practice.

Given the frequency of this presentation there has been a need to develop consistent approaches to treatment. Management guidelines produced by The British Society for Paediatric and Adolescent Rheumatology based on clinical consensus advocate a multidisciplinary approach including physiotherapy (PT), occupational therapy $(\mathrm{OT})$ and podiatry (Additional file 1), with an emphasis on self-management and delivered in clinical, home and school settings. The therapeutic interventions are often targeted at increasing muscle strength and proprioception in the affected joints and limbs [12-15]. However, objective evidence of their effectiveness is almost completely lacking [15].

\section{Methods}

\section{Objectives}

This study aimed to determine the effectiveness of a multidisciplinary care package in children diagnosed with symptomatic hypermobility by comparing a structured, bespoke programme of treatment delivered through a team of clinicians, physiotherapists and occupational therapists in clinical, home and school settings, with standard care.

\section{Design}

Prospective single centre randomised parallel group trial comparing an 8-week individualised multidisciplinary, multisite intervention programme (I) with current standard care (S).

\section{Setting}

Jenny Lind children's department at the Norfolk and Norwich University Hospital NHS Trust, UK. This is a regional centre for paediatric rheumatology referrals.

\section{Patients}

Children aged 5-16 years old referred to the paediatric rheumatology clinic between October 2010 and November 2012 were eligible for inclusion. Referrals came from community and general paediatrics, orthopaedics, physiotherapy and occupational therapy and general practice.

Patients were recruited between 7th of January 2011 and 14th of December 2012. The final twelve month follow-up assessments were conducted between the 5th of January 2012 and the 20th of December 2013.

\section{Inclusion criteria}

The service accepts referrals up to age 16 years old. In the absence of validated diagnostic criteria for symptomatic childhood hypermobility (or childhood JHS), children who were experiencing pain, functional or coordination problems considered to be secondary to hypermobility by an experienced paediatric rheumatologist were invited to take part, who met the following criteria:

A minimum Beighton score of 4 or more [16], or Bulbena score of 5 or more (males) and 6 or more (females) (see Table 1) [17].

Musculoskeletal pain in one or more areas of the body for at least 3 months duration.

\section{Exclusion criteria}

Participants were excluded if identified by an experienced consultant paediatric rheumatologist (KA) to have inflammatory joint disease, heritable disorder of connective tissue except Ehlers Danlos hypermobility type, presence of other chronic illness such as chronic pain syndrome or chronic fatigue syndrome using available diagnostic criteria [18-20]. Children under 5 years were excluded, anticipating they would have difficulty complying with the home exercise programme. In addition, children were excluded where, in the clinician's judgement they were unable to comply with the protocol .

\section{Baseline assessments}

Assessments were carried out by a designated paediatric physiotherapist (VE) assisted by the trial coordinator (LW). Written informed parental consent and patient assent was obtained. Demographic data were collected using a standardised questionnaire.

Specific evaluations included an assessment of: 
Table 1 Classification of hypermobility

\begin{tabular}{|c|c|c|c|}
\hline Site & Criterion & Beighton & Bulbena \\
\hline Thumb & Apposition to forearm & $x$ & $x$ \\
\hline 5th Metacarpophalangeal joint & Passive hyperextension $>90$ degrees & $x$ & $x$ \\
\hline Elbow & Hyperextension $>10$ degrees & $x$ & $x$ \\
\hline Knee hyperextension & Hyperextension > 10 degrees & $x$ & \\
\hline Trunk & Flexion to place hands flat on floor with legs straight & $x$ & \\
\hline Ankle & Dorsiflexion > 20 degrees & & $x$ \\
\hline Shoulder & External rotation $>85$ degrees & & $x$ \\
\hline Hip & Passive abduction $>85$ degrees & & $x$ \\
\hline Patella & Passive shift to lateral side of tibia & & $x$ \\
\hline 1st Metatarsophalangeal joint & Passive hyperextension $>90$ degrees & & $x$ \\
\hline Knee flexion & Heel to contact buttocks & & $x$ \\
\hline \multirow[t]{4}{*}{ Ecchymoses } & Presence after minimal trauma & & $x$ \\
\hline & Total point available & 9 & 10 \\
\hline & Score to determine hypermobility & 4 out of 9 & Males 5/10 \\
\hline & & & Females $6 / 10$ \\
\hline
\end{tabular}

Joint laxity, clinical evaluation of the extent and distribution of joint laxity by applying the Beighton and Bulbena scoring systems (Table 1).

Pain, using the Wong Baker faces pain scale (0-5) and self-reporting of sites of pain [21]. Children were asked to report their pain over the previous week. Parent reported pain, using a visual analogue scale (VAS) of $0-100$.

Physical function, using the Child Health Assessment Questionnaire (CHAQ) [22].

Health related quality of life (HRQoL) using the 9 dimensional Child Health Utility (CHU9D) [23]. Motor skills and coordination, using the Movement Assessment Battery for Children version 2 (M-ABC2) $[24,25]$.

Grip strength, using a standardised hand held pneumatic dynamometer (White Plains, New York) taking 3 readings and recording the highest achieved.

\section{Interventions}

All children with confirmed symptomatic hypermobility were offered standard management and given written information regarding the study. Those who showed an interest were contacted by the trial coordinator by telephone after a minimum of $48 \mathrm{~h}$ to answer any remaining questions and determine their willingness to take part. The trial coordinator contacted families both by telephone and in writing to achieve maximum retention of participants throughout the study. If no reply was received or if 3 re-scheduled appointments were not attended they were considered lost to follow up.

\section{Standard care group}

Standard care followed usual practice at the hospital and consisted of a single paediatric rheumatology clinic appointment (typically of around $30-40 \mathrm{~min}$ ) with a Paediatric Rheumatologist (KA) who diagnosed symptomatic hypermobility. All patients and families received verbal information and advice on management including discussing the biomechanical origin of the pain, the need for good muscle strength, examples of appropriate activities and a standard (Arthritis Research UK) information leaflet [26]. Referrals to PT, OT and orthotics were made where deemed clinically necessary.

\section{Multidisciplinary intervention group}

The multidisciplinary intervention was developed and refined by the research team following a systematic review of the literature [27], national consultation with specialist paediatric rheumatology therapy departments and informal consensus. The intervention comprised a programme of 3 individualised physiotherapy sessions addressing problem areas, and promoting improvements in stability and strength; gait analysis and provision of foot orthoses if needed; an OT assessment at the hospital clinic and at home; a joint physiotherapy and OT school visit to discuss the diagnosis with teachers and provide advice as necessary for both school and home. Children were given equipment depending on their needs. This included: a writing wedge, hand putty, pen grips, cutlery grips and a laptop computer. Those with problems in their hands received an OT directed hand exercise programme. The intervention was conducted by a 
second paediatric physiotherapist $(\mathrm{HB})$ and a paediatric occupational therapist (EJ). Both had access to baseline data in order to plan bespoke management.

Details of the specific structure of the intervention are listed below:

\section{Visit 1 (week 1)}

A joint treatment session with the occupational therapist (EJ) and physiotherapist (HB). Children were given an individualised programme of exercise devised to target symptomatic joints and problem areas. Exercises were selected from the PhysioTools $\odot$ manual. Information packs were supplied, and an orthotic appointment was arranged if deemed necessary.

\section{Visit 2 (week 2)}

An OT review at home which included an assessment of activities of daily living, use of aids, sleep, and leisure pursuits.

\section{Visit 3 (week 4)}

A school visit by both the physiotherapist and OT. This included the delivery of an education information pack and an assessment of difficulties in this environment. The child's overall mobility around school, handwriting, physical education, and school attendance was discussed with teachers, the child was not provided with any treatment on this visit.

\section{Visits 4 and 5 (weeks 6 and 8 )}

These visits took place at the Jenny Lind Children's Physiotherapy department at the Norfolk and Norwich University Hospital and were undertaken by the trial physiotherapist $(\mathrm{HB})$. The assessments reviewed the individual exercise programme initiated on week 1 and adapted and progressed treatment as necessary.

\section{Main outcome measures}

\section{Outcome measures}

The primary outcome measure was child reported pain (Wong-Baker scales). The secondary outcomes were parent-reported pain (100 mm VAS), physical function (CHAQ), HRQoL, coordination and grip strength. School attendance and requirement for health interventions were also recorded.

Primary and secondary outcome measures were assessed at 3 and 12 months after the baseline assessment. These outcomes were evaluated by trial physiotherapist (VE) who was blinded to the intervention group. Parents and children were specifically asked not to discuss their treatment with VE.

\section{Sample size}

It was estimated that we would need to randomise 100 children to either of the two treatment arms to detect a 0.5 SD change in pain score between the intervention and the standard care groups (at a nominal one-sided significance of 0.05 and $80 \%$ power). This was estimated using the sample size commands in STATA statistical software [28]. We aimed to recruit 125 children to accommodate a $20 \%$ drop out rate anticipated from previous reported trials. No adjustment for multiple testing was made.

\section{Randomisation}

The treatment groups were allocated randomly with minimisation used to achieve balance in group characteristics. The trial coordinator used a bespoke computer based method in the CTU remote from the research team. Three variables were utilised: age, gender and parent reported pain level.

\section{Statistical methods}

As over $90 \%$ of the sample attended all assessments, an intention to treat complete case analysis was conducted. Comparisons were made between the two groups for data that related to the 12-month period starting at the date that the first assessment was completed.

Between group comparisons were carried out in primary and secondary outcome measures for the differences between baseline values and values at three months and 12 months and baseline by t-tests for unadjusted analysis and linear regression models for analysis adjusted for age.

An ancillary analysis was conducted to examine the change in primary and secondary outcome measures over time. Multilevel regression modelling was used, with fixed effects for intervention, time and treatment $\mathrm{x}$ time, and random effects for the intercepts at each time point. The analyses were conducted using the STATA statistical software version 12 [28].

\section{Ethical approval}

The study was approved by the Norfolk Research ethics committee 09/H0310/80 on the 23rd of December 2009.

\section{Results}

A total of 157 children were assessed for eligibility by the paediatric rheumatologist (KA). Of these 38 were not randomised: 11 did not meet the eligibility criteria and 27 declined consent.

As illustrated in Fig. 1, 119 children were randomised, and 59 (50\%) received the intervention. Of these, 111 attended 3 month follow up and 105 attended 12 month follow up. Of the 59 randomised to the intervention, 56 (93.3\%) completed the multidisciplinary, 


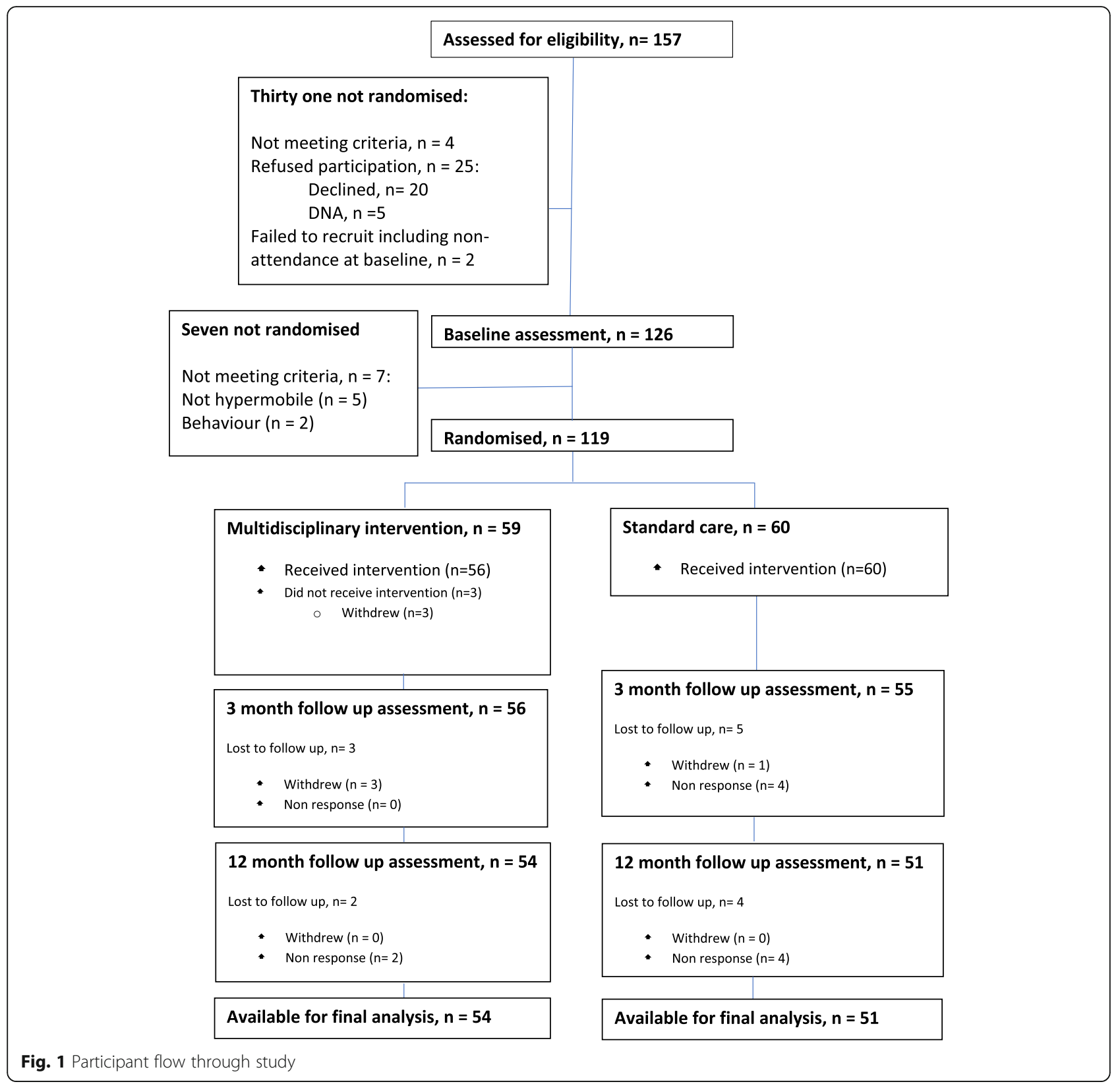

multisite programme. All 56 attended 3 month follow up and 54 (91.5\%) attended 12 month follow up. Of the 60 randomised to receive standard care, 55 (91.7\%) were assessed at 3 months and $51(85 \%)$ at 12 months. Overall the drop out was $6 \%$ at 3 months and a further $6 \%$ at 12 months.

\section{Characteristics of the sample}

The children's characteristics at their baseline assessment are shown in Table 2 and show no important differences between the two groups.

\section{Outcomes at 3 and 12 months}

Table 3 shows the between group differences in child pain as assessed by the Wong-Baker Faces scale between three months and baseline, and between 12 months and baseline. The level of pain improved in both groups at each of the follow up assessments; however, there was no significant difference in improvement between the two groups. A small improvement in child reported pain at 3 months was seen in the standard care group compared to the intervention group in the age adjusted data. Table 3 lists between group comparisons with baseline assessment for parent reported pain, parent reported 
Table 2 Baseline demographic and clinical data, including hypermobility and symptom scores

\begin{tabular}{lll}
\hline Characteristics & $\begin{array}{l}\text { Intervention } \\
(n=59)\end{array}$ & $\begin{array}{c}\text { Standard care } \\
(n=60)\end{array}$ \\
\hline Gender: male, $n$ (\%) & $27.0(45.8)$ & $27.0(45.0)$ \\
Age in years, mean (SD) & $9.47(3.18)$ & $9.35(3.20)$ \\
BMI, mean (SD) & $18.9(4.54)$ & $18.0(2.92)$ \\
Family history of JHS, $n$ (\%) & $11(18.6)$ & $17.0(28.3)$ \\
Child's pain assessment, mean (SD) & $2.19(1.36)$ & $3.53(1.63)$ \\
Parent's pain assessment, mean (SD) & $33.8(24.8)$ & $40.6(27.5)$ \\
Parent's reported physical function, mean (SD) & $0.84(0.620)$ & $0.860(0.72)$ \\
Child reported HRQoL, mean (SD) & $0.85(0.100)$ & $0.850(0.12)$ \\
Coordination, mean centile (SD) & $33.4(26.7)$ & $35.6(30.1)$ \\
Grip strength (kilopascals), mean (SD) & $57.0(25.0)$ \\
Beighton, mean (SD) & $5.80(1.50)$ & $59.4(31.7)$ \\
Bulbena, mean (SD) & $7.40(1.60)$ & $5.70(1.40)$ \\
Number of painful joints, mean (SD) & $1.80(2.1)$ & $7.70(1.30)$ \\
Participation in sport (number of sessions per week), mean (SD) & $2.60(2.30)$ \\
Absence from school due to MSK problem (individual instances in last 3 months), mean (SD) & $1.10(3.30)$ \\
GP attendance for MSK problem (individual instances in last 3 months), mean (SD) & $0.320(0.800)$ \\
Hospital attendance due to MSK problem (individual instances in last 3 months), mean (SD) & $1.10(0.800)$ & $2.10(2.50)$ \\
\hline
\end{tabular}

physical function, HRQoL, coordination and grip strength. No change was observed in the child reported HRQoL score (CHU9D) between groups or in either group throughout the study period. Coordination improved more than expected for age related gains at 3 months, but was not generally sustained at a year. As might be expected grip strength improved with age. None of the differences between groups was significant.

\section{Rate change in outcomes over time}

The multilevel regression model is shown in Table 4 and shows a significant mean improvement in child and parent reported pain, coordination and grip strength over the 12 months of follow up across the intervention and the standard care group taken together. However, neither the intervention itself, nor any of the individual patient characteristics considered separately (age, gender,

Table 3 Differences in primary and secondary outcomes at 3 and 12 months

\begin{tabular}{|c|c|c|c|c|c|c|}
\hline Factor & Standard care & Intervention & Unadjusted mean difference & $p$-value & Adjusted mean difference & $p$-value \\
\hline \multicolumn{7}{|c|}{3 Months change from baseline (outcome - baseline) } \\
\hline Child's pain assessment, mean (SD) & $-1.33(1.69)$ & $-0.73(1.55)$ & $0.6(-0.02,1.22)$ & 0.058 & $0.62(0.04,1.21)$ & 0.038 \\
\hline Parent's pain assessment mean (SD) & $-6.73(26.26)$ & $-3.27(28.64)$ & $3.46(-6.88,13.8)$ & 0.509 & $3.36(-7.01,13.72)$ & 0.522 \\
\hline $\begin{array}{l}\text { Parent's reported physical function, } \\
\text { mean (SD) }\end{array}$ & $-0.02(0.38)$ & $0.13(0.52)$ & $0.15(-0.02,0.33)$ & 0.088 & $0.15(-0.02,0.32)$ & 0.089 \\
\hline Child reported HRQoL, mean (SD) & $0.00(0.10)$ & $0.01(0.11)$ & $0.01(-0.03,0.05)$ & 0.493 & $0.01(-0.03,0.05)$ & 0.492 \\
\hline Coordination, mean (SD) & $7.57(20.26)$ & $6.21(19.54)$ & $-1.36(-8.88,6.16)$ & 0.721 & $-1.36(-8.92,6.19)$ & 0.721 \\
\hline Grip strength, mean (SD) & $2.32(12.03)$ & $1.12(13.87)$ & $-1.2(-6.18,3.78)$ & 0.634 & $-1.21(-6.19,3.77)$ & 0.632 \\
\hline \multicolumn{7}{|c|}{12 Months change from baseline (outcome - baseline) } \\
\hline Child's pain assessment, mean (SD) & $-1.58(1.92)$ & $-1.57(1.53)$ & $0.01(-0.66,0.69)$ & 0.967 & $0.06(-0.6,0.71)$ & 0.862 \\
\hline Parent's pain assessment mean (SD) & $-7.25(29.50)$ & $-6.81(27.30)$ & $0.44(-10.55,11.43)$ & 0.937 & $-0.08(-10.94,10.78)$ & 0.988 \\
\hline $\begin{array}{l}\text { Parent-reported physical function, } \\
\text { mean (SD) }\end{array}$ & $-0.02(0.38)$ & $0.04(0.55)$ & $0.06(-0.12,0.24)$ & 0.522 & $0.06(-0.13,0.24)$ & 0.546 \\
\hline Child reported HRQoL, mean (SD) & $-0.00(0.12)$ & $0.02(0.09)$ & $0.02(-0.02,0.06)$ & 0.244 & $0.03(-0.02,0.07)$ & 0.222 \\
\hline Coordination, mean (SD) & $10.75(19.46)$ & $3.83(20.75)$ & $-6.92(-14.76,0.92)$ & 0.083 & $-6.87(-14.75,1.02)$ & 0.087 \\
\hline Grip strength, mean (SD) & $7.29(16.05)$ & $4.72(17.16)$ & $-2.58(-9.05,3.89)$ & 0.431 & $-2.59(-9.1,3.92)$ & 0.432 \\
\hline
\end{tabular}




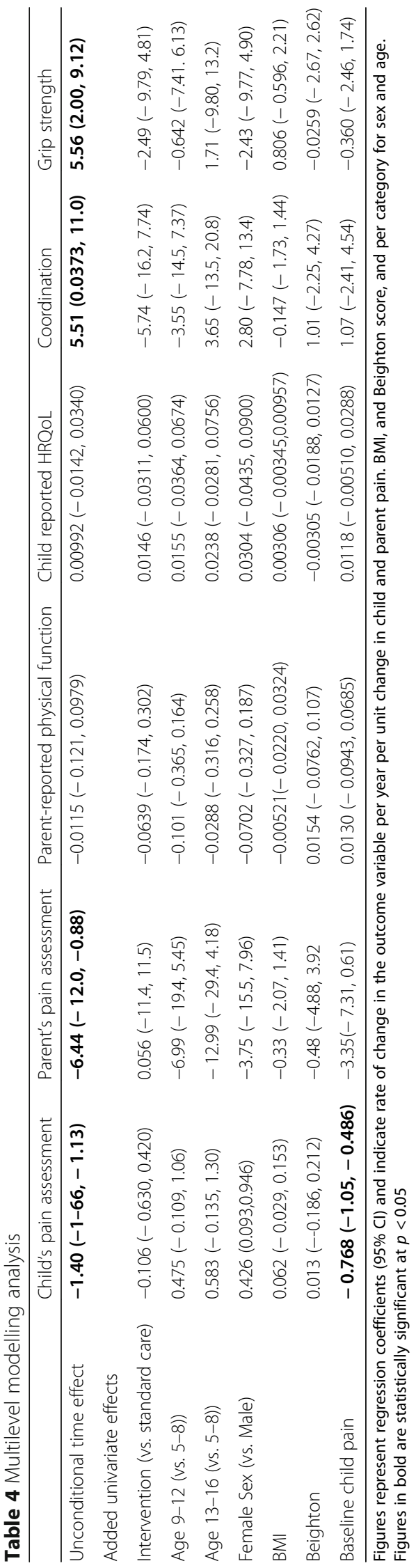


body mass index, and baseline degree of hypermobility) had a statistically significant impact on the rate of improvement over time. The self-reported baseline level of pain was a statistically significant determinant of 12-month outcome, with higher levels of baseline pain associated with more rapid mean reduction in pain score over time. A similar effect was seen for parent reported pain although it did not reach statistical significance.

\section{Discussion}

This randomised, single centre parallel group trial compared a structured multidisciplinary, multisite intervention programme with standard care in children with symptomatic hypermobility. No added benefit was seen from this intervention. Both treatment groups showed improvements in child and parent reported pain scores, coordination and grip strength after one year follow up. The self-reported HRQoL (as assessed by CHU9D) did not change in either group through the period of follow up. Our HRQoL scores for both groups remained within the normal reference range for healthy children [29, 30], suggesting that while children with symptomatic hypermobility experience a degree of pain and motor impairment, these symptoms tend not to limit their overall wellbeing compared to their healthy peers.

Clinicians faced with diagnosing and planning treatment for children with hypermobility and pain currently have very sparse evidence on which to base their decisions. A systematic review [27] identified only three robust studies on the management of hypermobility [14, 31, 32], only two of which were conducted in the paediatric population $[14,32]$ and just one was a randomised comparative trial [14]. The non-randomised studies conducted in children were limited in their scope and targeted single joint-specific areas associated with hypermobility (knee proprioception and handwriting) [31, 32]. The single randomised trial focused on physiotherapy and compared targeted with a general programme of treatment. As in our own study, children showed an improvement in pain through follow up with no evidence to favour any particular management strategy. However, interpretation is limited by the small size (57 participants) and consequent lack of power, and low retention rate (just 56\%). The influence of a fuller range of interventions that might be delivered by the multidisciplinary team has not been addressed.

The present study was designed to address the potential value of a multidisciplinary, multisite intervention package. Our intervention was developed through systematic literature review and clinical consensus, and adheres to the current British Society for Paediatric and Adolescent Rheumatology guidance. The intervention was designed for efficient delivery in a general hospital and community setting in a limited time.
This study has important limitations. We adopted a pragmatic approach to diagnosis, utilising a 'real world' clinical setting, and included children that an experienced paediatric rheumatologist diagnosed with symptomatic hypermobility. In taking this approach, we feel that the participants included reflect the broad range of the population referred to paediatric secondary and tertiary care and subsequently diagnosed with symptomatic hypermobility. Diagnostic criteria for JHS or Ehlers-Danlos hypermobility type (now termed hypermobility spectrum disorders and hypermobile EDS) [33, 34] have not been validated in the paediatric population. We applied Bulbena and Beighton scoring systems to confirm generalised hypermobility, to add face validity and to facilitate comparison with other published studies. The cut off values used conform to published literature, however population data on joint hypermobility scores across all age groups is still lacking. Higher cut off scores have been suggested but not validated $[1,34,35]$.

All participants received at least 'standard care' as an ethical requirement and could not be blinded to the interventions, which require active engagement. Participants gave fully informed consent and were therefore aware of the interventions in the treatment arm, which may have influenced behaviour. The trial coordinator recorded the number of therapy attendances in the preceding 3 months at each follow up appointment in all participants to ensure that the assessing physiotherapist (VE) remained fully blinded. We are aware that in the standard care arm 36 children $(60 \%)$ received at least one additional session of physiotherapy or occupational therapy and five received orthotics. Inevitably those randomised to the standard care group, irrespective of additional sessions, received a greater degree of attention than might have occurred outside an interventional trial.

We did not include direct measurement of child or parental anxiety in our study protocol. A systematic review of the literature conducted by our group has shown an association between anxiety and pain in children with hypermoblity [36]. It is possible that a reduction in anxiety due to clarification of the condition and education could have resulted in the improvements in pain seen across both groups.

A further limitation is the lack of validated outcome measures for symptomatic hypermobility in childhood. The pain measure used in the study assessed the intensity at the most prominent site and did not reflect the variable nature of pain or the variation in sites over the period assessed. The CHAQ is an assessment tool for children with juvenile idiopathic arthritis. It has not been validated for use in symptomatic hypermobility but has been used in a previous study [14]. It is conceivable that the outcome measures used may lack adequate sensitivity to detect a difference between the interventions. It is 
also possible that the sample size may have limited our ability to detect differences between the two intervention groups.

This study does not address whether hypermobile children report more pain compared to their non-hypermobile peers. In the multilevel model, there was no direct relationship between pain and degree of hypermobility and the degree of hypermobility was not related to level of symptom improvement or response to treatment. The data suggest that the relationship between the degree of joint mobility and a child's experience of pain is not direct.

\section{Conclusions}

We conclude that for children presenting with symptomatic hypermobility, standard care offered in routine practice in the UK is sufficient to lead to a sustained improvement in symptoms over a twelve-month period and that a more intensive multidisciplinary approach offers little further benefit. We recognise that symptomatic hypermobility is a heterogeneous condition and there may be subgroups that differ sufficiently to benefit from more intensive intervention [37, 38]. Nevertheless, our results suggest that for the majority the provision of education and positive interventions aimed at promoting healthy exercise and self-management leads to significant benefit without the need for more complex interventions. We believe our findings will help the development of prompt, simple and effective approaches to management, and will help diffuse beliefs about disability and negative consequences of this condition.

\section{Additional file}

Additional file 1: Guidelines for Management of Joint Hypermobility Syndrome in Children and Young People. (PDF $458 \mathrm{~kb}$ )

\begin{abstract}
Abbreviations
CHAQ: Child Health Assessment Questionnaire (An outcome measure to assess physical functioning level); CHU9D: Child Health Utility 9 dimensions (A validated tool to assess child reported health related quality of life/wellbeing); CTU: Clinical trials unit; EDS: Ehlers-Danlos Syndrome (an umbrella term for a collection of hereditary connective tissue disorders); HRQoL: Health related quality of life; JHS: Joint hypermobility syndrome; MABC2: Movement Assessment Battery for Children version 2 (a validated tool to assess childhood coordination); NHS: National Health Service (UK governement healthcare provider); UK: United Kingdom; VAS: Visual Analogue Scale $(100 \mathrm{~mm}$ line to determine level of pain experienced $0=$ no pain, 100 = maximum pain)
\end{abstract}

\section{Acknowledgements}

We would like to thank all the children, families and lay people who participated in the study. Without their participation, this important research would not have been possible.

\section{Funding}

This paper presents independent research funded by the National Institute for Health Research (NIHR) under its Research for Patient Benefit (RfPB) Programme (Grant Reference Number PB-PG-0407-13279). The views expressed are those of the author(s) and not necessarily those of the NHS, the NIHR or the Department of Health.

\section{Declarations}

Professor MacGregor affirms that the manuscript is an honest, accurate, and transparent account of the study being reported; that no important aspects of the study have been omitted; and any discrepancies from the study as planned have been explained.

\section{Data sharing}

The datasets used and/or analysed during the current study are available from the corresponding author on reasonable request.

\section{Research reporting checklist}

We have followed the CONSORT checklist for randomised controlled trials.

\section{Permissions}

No permissions are required. The protocol is attached as a separate document.

\section{Ethical approval and consent to participate}

The study was approved by the Norfolk Research ethics committee 09/ H0310/80

\section{Authors' contributions}

PB - made a substantial contributions to the analysis, and interpretation of data for the work, drafted the manuscript and was involved in its revision and approved the final version. VE - made a substantial contributions to the conception and design of the work; the acquisition of data and was involved in the critical revision of the manuscript and approved the final version. $\mathrm{HB}$ - made a substantial contributions to the conception and design of the work; the acquisition of data and was involved in the critical revision of the manuscript and approved the final version. EJ - made a substantial contributions to the conception and design of the work; the acquisition of data and approved the final version. LW - made a substantial contributions to the conception and design of the work; the acquisition of data and approved the final version. GB - made a substantial contributions to the conception and design of the work; was involved in the critical revision of the manuscript and approved the final version. AC - made a substantial contributions to the analysis of data for the work and approved the final version. KA - generated the original idea for the study, made a substantial contributions to the conception and design of the work; was involved in the recruitment of patients, the interpretation of data the critical revision of the manuscript and approved the final version. AJM - made a substantial contributions to the conception and design of the work, the analysis of data, critically revised the manuscript and approved the final version.

\section{Consent for publication}

All authors give full consent to publication.

\section{Competing interests}

The author declares that they have no competing interests.

\section{Publisher's Note}

Springer Nature remains neutral with regard to jurisdictional claims in published maps and institutional affiliations.

\section{Author details}

${ }^{1}$ Norfolk and Norwich University Hospital NHS Trust, Colney Lane, Norwich, UK. ${ }^{2}$ Norfolk Community Health and Care NHS Trust, Norwich, UK. ${ }^{3}$ Norwich Medical School, University of East Anglia, Norwich, UK.

Received: 5 September 2018 Accepted: 10 December 2018 Published online: 08 January 2019

\section{References}

1. Clinch J, Deere K, Sayers A, Palmer S, Riddoch C, Tobias JH, et al. Epidemiology of generalized joint laxity (hypermobility) in fourteen-year-old children from the UK: a population-based evaluation. Arthritis Rheum. 2011; 63(9):2819-27. 
2. Cheng JC, Chan PS, Hui PW. Joint laxity in children. J Pediatr Orthop. 1991; 11(6):752-6.

3. de Inocencio Arocena J, Ocaña Casas I, Benito Ortiz L. joint hypermobility: prevalence and relationship with musculoskeletal pain. Anales de pediatria. 2004;61(2):162-6.

4. Hasija RP, Khubchandani RP, Shenoi S. Joint hypermobility in Indian children. Clin Exp Rheumatol. 2008;26(1):146-50.

5. Lamari NM, Chueire AG, Cordeiro JA. Analysis of joint mobility patterns among preschool children. Sao Paulo Med J. 2005;123(3):119-23.

6. Seçkin U, Tur BS, Yilmaz O, Yağci I, Bodur H, Arasil T. The prevalence of joint hypermobility among high school students. Rheumatol Int. 2005;25(4):260-3.

7. Qureshi AU, Maalik A, Ahmad TM. Relationship of joint hypermobility and musculoskeletal problems and frequency of benign joint hypermobility syndrome in children. J Ayub Med Coll Abbottabad. 2010;22(4):150-4.

8. Engelbert RH, van Bergen M, Henneken T, Helders PJ, Takken T. Exercise tolerance in children and adolescents with musculoskeletal pain in joint hypermobility and joint hypomobility syndrome. Pediatrics. 2006;118(3): e690-6.

9. McCormack M, Briggs J, Hakim A, Grahame R. Joint laxity and the benign joint hypermobility syndrome in student and professional ballet dancers. J Rheumatol. 2004;31(1):173-8

10. Qvindesland A, Jonsson H. Articular hypermobility in Icelandic 12-year-olds. Rheumatology (Oxford). 1999;38(10):1014-6.

11. Ali H, Friswell M, Bell T, Foster HE. Triaging of referral letters to a fast track inflammatory arthritis clinic. Archives of Childhood Disease. 2004; 89(Supplement):(Suppl I):A44-A6.

12. Hakim A, Grahame R. Joint hypermobility. Best Pract Res Clin Rheumatol. 2003;17(6):989-1004

13. Simpson MR. Benign joint hypermobility syndrome: evaluation, diagnosis, and management. J Am Osteopath Assoc. 2006;106(9):531-6.

14. Kemp S, Roberts I, Gamble C, Wilkinson S, Davidson JE, Baildam EM, et al. A randomized comparative trial of generalized vs targeted physiotherapy in the management of childhood hypermobility. Rheumatology (Oxford). 2010; 49(2):315-25.

15. Engelbert RH, Juul-Kristensen B, Pacey V, de Wandele I, Smeenk S, Woinarosky $\mathrm{N}$, et al. The evidence-based rationale for physical therapy treatment of children, adolescents, and adults diagnosed with joint hypermobility syndrome/hypermobile Ehlers Danlos syndrome. American journal of medical genetics part C, seminars in medical. Genetics. 2017; 175(1):158-67.

16. Beighton P, Solomon L, Soskolne CL. Articular mobility in an African population. Ann Rheum Dis. 1973;32(5):413-8.

17. Bulbena A, Duro JC, Porta M, Faus S, Vallescar R, Martin-Santos R. Clinical assessment of hypermobility of joints: assembling criteria. J Rheumatol. 1992;19(1):115-22.

18. National Institute for Health and Care Excellence. [CG53] Chronic fatigue syndrome/myalgic encephalomyelitis (or encephalopathy): diagnosis and management 2007. https://www.nice.org.uk/guidance/cg53. Accessed 22 Nov 2018.

19. Loeys BL, Dietz HC, Braverman AC, Callewaert BL, De Backer J, Devereux RB, et al. The revised Ghent nosology for the Marfan syndrome. J Med Genet. 2010;47(7):476-85.

20. Beighton P, De Paepe A, Steinmann B, Tsipouras P, Wenstrup RJ. EhlersDanlos syndromes: revised nosology, Villefranche, 1997. Ehlers-Danlos National Foundation (USA) and Ehlers-Danlos support group (UK). Am J Med Genet. 1998;77(1):31-7.

21. Garra G, Singer AJ, Taira BR, Chohan J, Cardoz H, Chisena E, et al. Validation of the Wong-baker FACES pain rating scale in pediatric emergency department patients. Acad Emerg Med Off J Soc Acad Emerg Med. 2010; 17(1):50-4.

22. Singh G, Athreya BH, Fries JF, Goldsmith DP. Measurement of health status in children with juvenile rheumatoid arthritis. Arthritis Rheum. 1994;37(12): 1761-9.

23. Stevens K. Developing a descriptive system for a new preference-based measure of health-related quality of life for children. Qual Life Res. 2009; 18(8):1105-13.

24. Henderson SE, Sugen DA, Barnett A. Movement assessment battery for Children-2. 2nd edition (movement ABC-2). Examiner's manual. London: Pearson clinical; 2007.

25. Schoemaker MM, Niemeijer AS, Flapper BC, Smits-Engelsman BC. Validity and reliability of the movement assessment battery for Children-2 checklist for children with and without motor impairments. Dev Med Child Neurol. 2012;54(4):368-75.

26. Arthritis Research UK. Joint Hypermobility 2015. https://www. arthritisresearchuk.org/shop/products/publications/patient-information/ conditions/joint-hypermobility.aspx. Accessed 23 Nov 2018.

27. Smith $T O$, Bacon $H$, Jerman E, Easton V, Armon $K$, Poland F, et al. Physiotherapy and occupational therapy interventions for people with benign joint hypermobility syndrome: a systematic review of clinical trials. Disabil Rehabil. 2014;36(10):797-803.

28. StataCorp. Stata Statistical Software: Release 12. College Station, TX: StataCorp LP; 2011.

29. Stevens K, Ratcliffe J. Measuring and valuing health benefits for economic evaluation in adolescence: an assessment of the practicality and validity of the child health utility 9D in the Australian adolescent population. Value Health. 2012;15(8):1092-9.

30. Canaway AG, Frew EJ. Measuring preference-based quality of life in children aged 6-7 years: a comparison of the performance of the CHU-9D and EQ5D-Y--the WAVES pilot study. Qual Life Res. 2013;22(1):173-83.

31. Sahin N, Baskent A, Cakmak A, Salli A, Ugurlu H, Berker E. Evaluation of knee proprioception and effects of proprioception exercise in patients with benign joint hypermobility syndrome. Rheumatol Int. 2008;28(10):995-1000.

32. Frohlich L, Wesley A, Wallen M, Bundy A. Effects of neoprene wrist/hand splints on handwriting for students with joint hypermobility syndrome: a single system design study. Phys Occup Ther Pediatr. 2012;32(3):243-55.

33. Castori M, Tinkle B, Levy H, Grahame R, Malfait F, Hakim A. A framework for the classification of joint hypermobility and related conditions. Am J Med Genet C: Semin Med Genet. 2017;175(1):148-57.

34. Malfait F, Francomano C, Byers P, Belmont J, Berglund B, Black J, et al. The 2017 international classification of the Ehlers-Danlos syndromes. American journal of medical genetics part C, seminars in medical. Genetics. 2017; 175(1):8-26

35. Smits-Engelsman B, Klerks M, Kirby A. Beighton score: a valid measure for generalized hypermobility in children. J Pediatr. 2011;158(1):119-23, 23.e1-4.

36. Smith TO, Easton V, Bacon H, Jerman E, Armon K, Poland F, et al. The relationship between benign joint hypermobility syndrome and psychological distress: a systematic review and meta-analysis. Rheumatology (Oxford). 2014:53(1):114-22.

37. Pacey V, Adams RD, Tofts L, Munns CF, Nicholson LL. Joint hypermobility syndrome subclassification in paediatrics: a factor analytic approach. Arch Dis Child. 2015;100(1):8-13.

38. Scheper MC, Nicholson LL, Adams RD, Tofts L, Pacey V. The natural history of children with joint hypermobility syndrome and Ehlers-Danlos hypermobility type: a longitudinal cohort study. Rheumatology (Oxford). 2017:56(12):2073-83

\section{Ready to submit your research? Choose BMC and benefit from:}

- fast, convenient online submission

- thorough peer review by experienced researchers in your field

- rapid publication on acceptance

- support for research data, including large and complex data types

- gold Open Access which fosters wider collaboration and increased citations

- maximum visibility for your research: over $100 \mathrm{M}$ website views per year

At $\mathrm{BMC}$, research is always in progress.

Learn more biomedcentral.com/submission 